\title{
Uveitis Presented as a Case of Ocular Syphilis - A Rare Presentation
}

\author{
Asrul Abdul Wahab ${ }^{1}$, Norhazlin Mustafa ${ }^{2}$
}

\begin{abstract}
:
Ocular syphilis is one of the clinical presentation or complication of syphilis. Uveitis is the most common ocular diagnosis of the condition but any component of the eyes can be affected. Serology test that include both treponemal and non-treponemal antibody detections play an important role for supporting the diagnosis. This condition is considered as part of neurosyphilis and the recommended treatment follows the treatment for neurosyphilis.

We reported a 47-year-old man presented with chronic episode of blurring of vision associated with floaters involving both eyes. Both eyes showed abnormal visual acuity with involvement of optic disc on the left eye. Serology tests for non-treponemal antibody and treponemal antibody test were positive. He was diagnosed as a case of bilateral posterior uveitis with left eye neuroretinitis. He was successfully treated with intravenous aqueous crystalline penicillin 3 million unit every four hour daily for 14 days.
\end{abstract}

Keywords: Neurosyphilis, Ocular syphilis, Syphilis IgM, Uveitis.

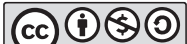

DOI: http://dx.doi.org//0.3329/jom.v20il.3884I

Copyright: (C) 2019 WahabAA et al. This is an open access article published under the Creative Commons Attribution-NonCommercial-NoDerivatives 4.0 International License, which permits use, distribution and reproduction in any medium, provided the original work is properly cited, is not changed in any way and it is not used for commercial purposes.

Received: 17 June, 2018;

Accepted: 27 September, 2018

\section{Introduction:}

Syphilis is a sexually transmitted infection caused by a spirochete Treponema pallidum. The infection can manifest in various clinical presentations and typically are divided into several stages. The early syphilis includes primary, secondary and early latent stage while late syphilis includes late latent and tertiary syphilis. Ocular syphilis is one of the clinical presentations of syphilis. Even though rare, it can manifest at any stage of the infection. Previous data from our center showed that four out of 63 cases of syphilis were diagnosed as possible neurosyphilis. ${ }^{1}$ Active ocular syphilis should be considered as secondary syphilis and neurosyphilis. ${ }^{2}$

1. Medical Microbiologist, Department of Medical Microbiology and Immunology, Faculty of Medicine, Universiti Kebangsaan Malaysia, Cheras, Kuala Lumpur, Malaysia.

2. Medical Microbiologist, Institute Medical Research, Kuala Lumpur Malaysia.

Corresponding author: Asrul Abdul Wahab, Department of Medical Microbiology and Immunology, Faculty of Medicine, Universiti Kebangsaan Malaysia, 56000 Cheras,Kuala Lumpur, Malaysia. Email: saw@ppukm.ukm.edu.my.

\section{Case Presentation:}

A 47-year-old Malay man was referred to Eye Clinic with problem of blurring of vision involving both eyes for four months. The condition was associated with floaters but no eye pain or discomfort. There were no other symptoms related to his main complaint. He denied of any history of trauma to the eyes. He was able to do his routine daily activities despite of this problem. He was a retired army personnel and now works as a tourist guide.

On examination, he was afebrile with normal blood pressure and pulse rate. Examination of both eyes noted reduced in visual acuity for both eyes with right eye at $6 / 24$ while left eye was $6 / 36$. The relative afferent pupillary defect (RAPD) was positive on the left eye. The slit lamp examination was normal on both eyes. The optic disc was hyperemic on the left eye. Both eyes had normal intraocular pressure and anterior segments. No choroiditis and vasculitis were found by fundus fluorescein angiography (FFA). Neurological and cranial nerve examinations were unremarkable. Examination of the other body systems was also normal.

Blood specimen was sent to the laboratory for several investigations. His white cell count and hemoglobin were normal. The antinuclear antibody test and rheumatoid factor 
were negative. The rapid plasma reagin (RPR) was reactive at significantly high titration, 1:256. The treponema antibody test by Syphilis IgM and IgG were positive. Human immunodeficiency virus (HIV) screening was negative. Other laboratory results on the day of admission were as shown in Table 1. Because of positive serology test for syphilis, further history regarding risk factor was further investigated. He revealed the history of sexual contact with commercial sex worker several years ago and had experienced urethral discharged subsequently. He was treated for gonorrhea at that time and denied any history of genital ulcer.

Table 1: Laboratory results on the day of admission.

\begin{tabular}{lcc}
\hline Laboratory Tests & Result & Normal Range \\
\hline White cell count & $8.8 \times 10^{9} / \mathrm{L}$ & $\left(4.1-11.4 \times 10^{9} / \mathrm{L}\right)$ \\
Hemoglobin & $15.3 \mathrm{~g} / \mathrm{dL}$ & $(13.5-17.4 \mathrm{~g} / \mathrm{dL})$ \\
Platelet & $319 \times 10^{9} / \mathrm{L}$ & $\left(142-350 \times 10^{9} / \mathrm{L}\right)$ \\
Natrium & $137 \mathrm{mmol} / \mathrm{L}$ & $(135-150 \mathrm{mmol} / \mathrm{L})$ \\
Potassium & $5.0 \mathrm{mmol} / \mathrm{L}$ & $(3.5-5.0 \mathrm{mmol} / \mathrm{L})$ \\
Urea & $3.5 \mathrm{mmol} / \mathrm{L}$ & $(2.5-6.4 \mathrm{mmol} / \mathrm{L})$ \\
C-reactive protein & $0.20 \mathrm{mg} / \mathrm{dL}$ & $(<0.5 \mathrm{mg} / \mathrm{dL})$ \\
Alanine transaminase & $13 \mathrm{U} / \mathrm{L}$ & $<44 \mathrm{U} / \mathrm{L}$ \\
\hline
\end{tabular}

Following that, he was diagnosed as bilateral posterior uveitis with left eye neuroretinitis secondary to syphilis infection. He was admitted to the ward and was given intravenous aqueous crystalline penicillin 3 millions unit four hourly daily for 14 days. He was discharged after completed his antibiotic regime. He refused for lumbar puncture for cerebrospinal fluid analysis. His vision improved tremendously at 6 weeks post treatment. The RPR titration was declining to 1:64 at 3 months and subsequently to $1: 16$ at 6 months post treatment.

\section{Discussion:}

Ocular syphilis is a rare clinical presentation or complication of syphilis. It was reported to occur in $0.6 \%$ of syphilis infection. ${ }^{3}$ Ocular syphilis can occur at any stage of syphilis, affecting any component of the eye and often associated with neurosyphilis. The condition is mainly diagnosed in young adult as previously reported in various studies with mean age between 43 to 50 years. ${ }^{3,4,5}$ The case highlighted here was also diagnosed at the age of 47 years. As described in many reports, it occurs predominantly in male and most were belonged to men sex with men population. ${ }^{3,6}$ This patient denied any homosexual activity.
Clinical manifestations of ocular syphilis can be varied widely. Blurry of vision was the main clinical complaint of this patient and it was the most common clinical manifestation experienced by the patients in previous reports. ${ }^{3,5,7}$ Another important associated features include floater as experienced in this case and ocular pain. ${ }^{5,7}$ It is important to highlight that some patients may not have any symptoms and were diagnosed incidentally during ocular examination. ${ }^{7}$ Uveitis as diagnosed in this case is the most common ocular diagnosis for the condition. ${ }^{3,5}$ Position of the uveitis may be related to HIV status of the patient. Patient with HIV coinfection tends to present with posterior or pan uveitis. ${ }^{6}$ Isolated anterior uveitis is perhaps only seen in non-HIV patients as described previously. ${ }^{7}$ However, this does not apply to this case as the patient was noted to have posterior uveitis and he was HIV negative.

The diagnosis of ocular syphilis is made with the help of serology test. In most laboratories, this will include performing both non-treponemal antibody tests such as RPR or VDRL, and treponemal antibody test. In ocular syphilis, regardless of the stage of syphilis, both types of serology tests are positive. ${ }^{4,5}$ Similar findings were noted in this patient. Ocular syphilis is perhaps more common in secondary syphilis and in secondary syphilis both types of serology tests produce high sensitivity. HIV positive patients with ocular syphilis tend to present at higher VDRL or RPR titration (range 1:64 to 1:16384) than HIV-negative patients. ${ }^{4}$ Treponema pallidum specific IgM is an added value for the diagnosis of syphilis and probably in diagnosis of ocular syphilis. IgM is the earliest antibody to be produced in syphilis infection. IgM may persist in the blood of the infected individual for certain duration. It is commonly detected in primary and secondary but less common in latent and tertiary syphilis. ${ }^{8.9,10}$ The concentration of $\operatorname{IgM}$ was described to decrease following appropriate treatment for syphilis. Patients with primary or secondary syphilis generally have undetectable $\operatorname{IgM}$ at 6 months after treatment. ${ }^{8}$ Positive Treponema pallidum specific IgM generally reflects active infection and the treatment is perhaps needed. ${ }^{8,10,11}$ In this case, the patient was non-HIV but presented with high RPR titration at 1:256 and positive Treponema pallidum IgM most likely to indicate very active disease.

Patient with ocular syphilis should be treated in similar way to neurosyphilis. Cerebrospinal analysis should be included as part of diagnostic work up even if the patient does not complaint of any symptoms related to neurosyphilis, the neurological and radiological examination is normal. Ocular syphilis is perhaps the solitary manifestation of 
neurosyphilis in patients without abnormal neurological and radiological examinations but reactive VDRL in cerebrospinal fluid specimen. ${ }^{4}$ The recommended treatment regime for neurosyphilis is intravenous aqueous crystalline penicillin G 18-24 millions unit per day, administered as 3-4 millions unit four hourly or as continuous infusion for 10-14 days. ${ }^{12}$ Both patients with HIV and without HIV co-infection were noted to have their vision restored following appropriate treatment. ${ }^{13}$ Among the non-HIV patients, it was noted that all of them had seroreversion at the end of follow up. ${ }^{5}$ The patient in this case was given antibiotic regime for neurosyphilis and had a favourable outcome clinically and serologically.

\section{Conclusion:}

Ocular syphilis is rare but serology test for syphilis should be included in laboratory work up for diagnosis. Ocular syphilis is an active syphilis and most of the time both nontreponemal and treponemal antibody test are positive. Specific Treponema pallidum IgM may help to differentiate between early and late syphilis, as positive $\operatorname{IgM}$ is most likely to indicate early infection. Appropriate treatment results in favorable outcome regardless of HIV status.

\section{Acknowledgement:}

Authors would like to thank the Dean of Faculty of Medicine, Universiti Kebangsaan Malaysia for supporting us to publish this case report.

\section{Conflict of interest: None}

\section{References:}

1. Wahab AA, Ramli MEA, Mustafa RAM, Lim GMW, Wan Sahimi WN, Husyairi H, et al. Sero-epidemiology of syphilis in a tertiary teaching hospital in Kuala Lumpur. Bangladesh Journal of Medical Science. 2018:17(01);62-66.

2. Davis JL. Ocular syphilis. Curr Opin Ophthalmol. 2014:25;513-518. https://doi.org/10.1097/ICU.0000000000000099

3. Oliver SE, Aubin M, Atwell L, Matthias J, Cope A, Mobley $\mathrm{V}$, et al. Ocular syphilis-eight jurisdictions, United States,
2014-2015. MMWR. 2016:65(43);1185-1188. https:// doi.org/10.15585/mmwr.mm6543a2

4. Lee SY, Cheng V, Rodger D, Rao N. Clinical and laboratory characteristics of ocular syphilis: a new face in the era of HIV co-infection. Journal of Ophthalmic Inflammation and Infection. 2015:5(26)1-7. https://doi.org/10.1186/s12348015-0056-x

5. Zhu J, Jiang Y, Shi Y, Zheng B, Xu Z, Jia W. Clinical manifestations and treatment outcomes of syphilitic uveitis in HIV-negative patients in China a prospective case study. Medicine. 2017:96;43(e8376). https://doi.org/10.1097/ MD.0000000000008376

6. Fonollosa A, Martinez-Indart L, Artaraz J, MartinezBerriotxoa A, Agirrebengoa K, Garcia M, et al. Clinical manifestations and outcomes of syphilis-associated uveitis in Northern Spain. Ocular Immunology \& Inflammation. 2014:1-6. https://doi.org/10.3109/09273948.2014.943349

7. Yap SC, Tan YL, Chio MTW, Teoh SC. Syphilitic uveitis in a Singaporean population. Ocular Immunology \& Inflammation. 2014:22(1);9-14. https://doi.org/10.3109/ 09273948.2013.829106

8. Pedersen NS, Petersen CS, Axelsen NH. Enzyme-linked immunosorbent assay for detection of immunoglobulin-M antibody against the Reiter treponem flagellum in syphilis. Journal of Clinical Microbiology. 1982:Oct;608-614.

9. Knaute DF, Graf N, Lautenschlager S, Weber R, Bosshard P. Serological response to treatment of syphilis according to disease stage and HIV status. CID. 2012;55:1615-1622. https://doi.org/10.1093/cid/cis757

10. Merlin S, Andre J, Alacoque B, Paris-Hamelin A. Importance of specific IgM antibodies in 116 patients with various stages of syphilis. Genitourin Med. 1985;65:82-7. https://doi.org/ 10.1136/sti.61.2.82

11. Bosshard PP. Usefulness of IgM-specific enzyme immunoassays for serodiagnosis of syphilis: Comparative evaluation of three different assays. Journal of Infection. 2013;67:35-42. https://doi.org/10.1016/j.jinf.2013.03.011

12. https://www.cdc.gov/std/tg2015/syphilis.htm

13. Cunningham ET, Eandi CM, Pichi F. Syphilitic uveitis. Ocular Immunology \& Inflammation. 2014:22(1);2-3. https://doi.org/ $10.3109 / 09273948.2014 .883236$ 